\title{
SIFAT ALJABAR BANACH KOMUTATIF DAN ELEMEN IDENTITAS PADA KELAS $\boldsymbol{D}(K)$
}

\author{
Malahayati \\ Program Studi Matematika Fakultas Sains dan Teknologi UIN Sunan Kalijaga Yogyakarta \\ e-mail: malahayati_01@yahoo.co.id
}

\begin{abstract}
ABSTRAK
Himpunan semua fungsi Baire kelas satu yang terbatas pada $K$ ditulis $B_{1}(K)$, dengan $K$ sembarang ruang metrik separabel. Salah satu kelas bagian terpenting dari $B_{1}(K)$ adalah $D(K)$, yang menotasikan kelas semua fungsi pada $K$ yang merupakan selisih fungsi-fungsi semikontinu terbatas pada $K$. Pada paper ini dibuktikan bahwa sifat aljabar Banach komutatif dan elemen identitas berlaku di kelas $D(K)$.
\end{abstract}

Kata kunci: Ruang metrik separabel, Aljabar Banach, Baire Kelas Satu, fungsi semikontinu, kelas $\boldsymbol{D}(\boldsymbol{K})$.

\section{ABSTRACT}

The first Baire class of bounded functions on separable metric spaces $K$ denoted by $B_{1}(K)$. One of the most important subclass of $B_{1}(K)$ is $D(K)$, by $D(K)$ is denoted the class of all functions on $K$ which are differences of bounded semicontinuous functions. In this paper we proved that $D(K)$ is abelian Banach algebra and identity element.

Keywords: Separable metric spaces, Banach Algebra, The first Baire class, Semicontinuous functions, The Class $D(K)$

\section{PENDAHULUAN}

Himpunan semua fungsi Baire kelas satu yang terbatas pada $K$ ditulis $B_{1}(K)$, dengan $K$ sembarang ruang metrik separabel. Salah satu kelas bagian terpenting dari $B_{1}(K)$ adalah $D(K)$, yang menotasikan kelas semua fungsi pada $K$ yang merupakan selisih fungsi-fungsi semikontinu terbatas pada $K$. Kelas $D(K)$ pertama kali dikenalkan oleh A.S Kechris dan Louveau pada tahun 1990. Banyak peneliti yang telah membahas tentang kelas fungsi $D(K)$. Sejalan dengan kemajuan sains dan teknologi, kajian tentang $D(K)$ juga mengalami perkembangan sehingga muncul beberapa pengertian tentang $D(K)$ dan norma pada $D(K)$, seperti yang ditulis oleh Haydon, Odell, Rosenthal (1991) dan Rosenthal (1994) serta Farmaki (1996). Kelas fungsi $D(K)$ memiliki peranan penting dalam cabang matematika diantaranya analisis fungsional, khususnya dalam pengaplikasian teori ruang Banach. Oleh karena itu penulis tertarik untuk membuktikan sifat aljabar Banach komutatif dengan elemen identitas pada kelas $D(K)$.

\section{TEORI DASAR}

Pada bagian ini akan diberikan beberapa pengertian dasar dan sifat yang merupakan konsep awal untuk dipahami agar mudah mengikuti pembahasan selanjutnya. Pengertianpengertian dan sifat-sifat yang disajikan diadopsi dari beberapa literatur yang disebutkan pada daftar pustaka.

Definisi 2.1 (Aljabar Banach) Aljabar adalah ruang linear $A$ yang di dalamnya didefinisikan operasi multiplikasi sehingga untuk setiap $x, y, z \in$ A dan skalar $\alpha$, berlaku

1) $x y \in A$

2) $x(y z)=(x y) z$

3) $x(y+z)=x y+x z$

4) $(x+y) z=x z+y z$

5) $\alpha(x y)=(\alpha x) y=x(\alpha y)$.

Selanjutnya A dikatakan komutatif (abelian) jika untuk setiap $x, y \in A$ berlaku $x y=y x$. Aljabar $A$ dikatakan mempunyai elemen identitas jika terdapat dengan tunggal elemen $e \neq \mathbf{0}$ sehingga ex $=x e=x$ untuk setiap $x \in A$. Elemen $e$ ini disebut elemen identitas. Aljabar bernorma A ialah suatu aljabar yang dilengkapi dengan norma \|. \| sehingga $\|x y\| \leq\|x\|\|y\|$ untuk setiap $x, y \in A$. Sedangkan aljabar bernorma yang lengkap disebut aljabar Banach.

Selanjutnya diberikan definisi fungsi semikontinu, yang akan digunakan dalam mendefinisikan kelas fungsi $D(K)$. Fungsi - fungsi yang dibicarakan bernilai real dan didefinisikan pada $E$, dengan $E$ himpunan bagian dari ruang metrik $X$. Sebelumnya disepakati terlebih dahulu bahwa setiap pengambilan infimum dan supremum dari suatu himpunan pada bagian ini, 
himpunan yang dimaksud merupakan himpunan bagian dari $\overline{\boldsymbol{R}}$, dengan $\overline{\boldsymbol{R}}=\boldsymbol{R} \cup\{-\infty, \infty\}$. Dalam mendefinisikan fungsi semikontinu diperlukan konsep limit atas dan limit bawah, oleh karena itu akan diberikan definisi limit atas dan limit bawah terlebih dahulu.

Definisi 2.2 (Limit atas dan Limit Bawah) Diberikan fungsi $f$ yang di definisikan pada $E$ dan $x_{0} \in E$.

1) Limit atas (upper limit) fungsi $f$ ketika $x$ mendekati $x_{0}$ ditulis dengan $\varlimsup_{x \rightarrow x_{0}} f(x)$ dan didefinisikan

$$
\varlimsup_{x \rightarrow x_{0}} f(x)=\inf \left\{M_{\varepsilon}\left(f, x_{0}\right): \varepsilon>0\right\},
$$

dengan $M_{\varepsilon}\left(f, x_{0}\right)=\sup \left\{f(x): x \in N_{\varepsilon}\left(x_{0}\right) \cap\right.$ $E\}$.

2) Limit bawah (lower limit) fungsi $f$ ketika $x$

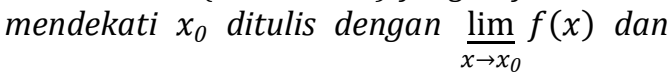
didefinisikan

$$
\varliminf_{x \rightarrow x_{0}} f(x)=\sup \left\{m_{\varepsilon}\left(f, x_{0}\right): \varepsilon>0\right\},
$$

dengan $m_{\varepsilon}\left(f, x_{0}\right)=\inf \left\{f(x): x \in N_{\varepsilon}\left(x_{0}\right) \cap\right.$ E\}.

Pada Definisi 2 diatas, nilai limitnya selalu ada dan dapat bernilai berhingga, $+\infty$, atau $-\infty$.

Definisi 2.3 (Fungsi Semikontinu) Diberikan fungsi $f$ yang didefinisikan pada $E$ dan $x_{0} \in E$.

1) Fungsi $f$ dikatakan semikontinu atas (upper semicontinuous) di $x_{0}$ apabila $f\left(x_{0}\right)=$ $\varlimsup_{x \rightarrow x_{0}} f(x)$. Selanjutnya, fungsi $f$ dikatakan semikontinu atas pada $E$ apabila fungsi $f$ semikontinu atas disetiap $x_{0} \in E$.

2) Fungsi $f$ dikatakan semikontinu bawah (lower semicontinuous) di $x_{0}$ apabila $f\left(x_{0}\right)=\lim _{x \rightarrow x_{0}} f(x)$. Selanjutnya, fungsi $f$ dikatakan semikontinu bawah pada $E$ apabila fungsi $f$ semikontinu bawah disetiap $x_{0} \in E$.

3) Fungsi yang semikontinu atas atau semikontinu bawah dinamakan fungsi semikontinu.

Pada pembuktian sifat-sifat kelas $D(K)$, pemakaian definisi kelas $D(K)$ secara langsung cukup menyulitkan. Oleh karena itu, diperlukan suatu hasil yang lebih memudahkan dalam pembahasan yang dimaksud. Fungsi-fungsi yang dibicarakan bernilai real dan didefinisikan pada $K$, dengan $K$ sebarang ruang metrik separabel. Selain itu, himpunan semua fungsi-fungsi kontinu pada $K$ dinotasikan dengan $C(K)$.

Lemma 2.4 Fungsi $f \in D(K)$ jika dan hanya jika terdapat fungsi-fungsi semikontinu bawah terbatas $u$ dan $v$ pada $K$, sehingga $f=u-v$.
Bukti : (Syarat cukup). Diketahui fungsi-fungsi semikontinu bawah terbatas $u$ dan $v$ pada $K$, sehingga $f=u-v$. Menurut definisi $D(K)$, jelas $f \in D(K)$.

(Syarat perlu). Diketahui $f \in D(K)$, berarti terdapat fungsi-fungsi semikontinu terbatas $u$ dan $v$ pada $K$, sehingga $f=u-v$. Dalam hal ini ada beberapa kemungkinan, yaitu:

Kemungkinan pertama: Jika $u$ dan $v$ fungsi-fungsi semikontinu atas terbatas pada $K$, maka diperoleh $f=u-v=(-v)-(-u)$. Karena $u$ dan $v$ fungsifungsi semikontinu atas, maka $-u$ dan $-v$ fungsifungsi semikontinu bawah. Oleh karena itu, apabila $u^{\prime}=-v$ dan $v^{\prime}=-u$ maka diperoleh $u^{\prime}$, $v^{\prime}$ fungsi-fungsi semikontinu bawah terbatas pada $K$ dan $f=u^{\prime}-v^{\prime}$.

Kemungkinan kedua: Jika $u$ fungsi semikontinu bawah terbatas pada $K$ dan $v$ fungsi semikontinu atas terbatas pada $K$, maka $f=u-v=(u-v)-$ 0 . Karena $v$ fungsi semikontinu atas, maka $-v$ fungsi semikontinu bawah sehingga $u-v$ fungsi semikontinu bawah. Oleh karena itu, apabila $u^{\prime}=$ $u-v$ dan $v^{\prime}=0$ maka diperoleh $u^{\prime}, v^{\prime}$ fungsifungsi semikontinu bawah terbatas pada $K$ dan $f=u^{\prime}-v^{\prime}$.

Kemungkinan ketiga : Jika $u$ fungsi semikontinu atas terbatas pada $K$ dan $v$ fungsi semikontinu bawah terbatas pada $K$, maka $f=u-v=0-$ $(v-u)$. Karena $u$ fungsi semikontinu atas, maka $-u$ fungsi semikontinu bawah sehingga $v-u$ fungsi semikontinu bawah. Oleh karena itu, jika $u^{\prime}=0$, dan $v^{\prime}=v-u$ maka diperoleh $u^{\prime}, v^{\prime}$ fungsi-fungsi semikontinu bawah terbatas pada $K$ $\operatorname{dan} f=u^{\prime}-v^{\prime}$

Untuk selanjutnya, apabila $f$ sebarang fungsi yang didefinisikan pada $K$, notasi $f \geq 0$ dimaksudkan $f(x) \geq 0$ untuk semua $x \in K$.

Lemma 2.5 Fungsi $f \in D(K)$ jika dan hanya jika terdapat fungsi-fungsi semikontinu bawah terbatas $u, v \geq 0$ pada $K$, sehingga $f=u-v$.

Bukti : (Syarat cukup). Diketahui fungsi-fungsi semikontinu bawah terbatas $u, v \geq 0$ pada $K$ sehingga $f=u-v$. Oleh karena itu, menurut Lemma 4 di atas, jelas $f \in D(K)$.

(Syarat perlu). Diketahui $f \in D(K)$, maka menurut Lemma 4 terdapat fungsi-fungsi semikontinu bawah terbatas $g$ dan $h$ pada $K$ sehingga $f=g-h$. Karena $g$ fungsi semikontinu bawah terbatas pada $K$, maka terdapat barisan $\left\{\varphi_{n}\right\}$ di $C(K)$ sehingga $\varphi_{0} \leq \varphi_{1} \leq \varphi_{2} \leq \varphi_{3} \leq \cdots \leq$ $\varphi_{n} \leq \varphi_{n+1} \leq \cdots$ dengan $\varphi_{0}=\mathbf{0}$ dan $\left\{\varphi_{n}\right\}$ konvergen titik demi titik ke $g$. Oleh karena itu, diperoleh 


$$
\begin{aligned}
& g(x)=\lim _{n \rightarrow \infty} \varphi_{n}(x) \\
& =\lim _{n \rightarrow \infty} \sum_{j=1}^{n}\left(\varphi_{j}-\varphi_{j-1}\right)(x) \\
& =\sum_{j=1}^{\infty}\left(\varphi_{j}-\varphi_{j-1}\right)(x),
\end{aligned}
$$

untuk setiap $x \in K$. Selanjutnya, karena $h$ juga fungsi semikontinu bawah terbatas pada $K$, maka terdapat barisan $\left\{\psi_{n}\right\} \subseteq C(K)$ sehingga $\psi_{0} \leq$ $\psi_{1} \leq \psi_{2} \leq \psi_{3} \leq \cdots$ dengan $\psi_{0}=\mathbf{0}$ dan $\left\{\psi_{n}\right\}$ konvergen titik demi titik ke $h$. Oleh karena itu, diperoleh

$$
\begin{aligned}
& h(x)=\lim _{n \rightarrow \infty} \psi_{n}(x) \\
& =\lim _{n \rightarrow \infty} \sum_{j=1}^{n}\left(\psi_{j}-\psi_{j-1}\right)(x)=\sum_{j=1}^{\infty}\left(\psi_{j}-\psi_{j-1}\right)(x), \\
& \text { untuk setiap } x \in K . \text { Akibatnya, untuk sebarang } \\
& x \in K \text { diperoleh } \\
& f(x)=g(x)-h(x)=\sum_{j=1}^{\infty}\left(\varphi_{j}-\varphi_{j-1}\right)(x)- \\
& \sum_{j=1}^{\infty}\left(\psi_{j}-\psi_{j-1}\right)(x) .
\end{aligned}
$$

Selanjutnya, namakan $u=\sum_{j=1}^{\infty}\left(\varphi_{j}-\varphi_{j-1}\right)$ dan $v=\sum_{j=1}^{\infty}\left(\psi_{j}-\psi_{j-1}\right)$. Karena $\varphi_{j}-\varphi_{j-1} \geq 0$ dan $\psi_{j}-\psi_{j-1} \geq 0$ untuk setiap $j=1,2, \cdots$, maka diperoleh $u, v \geq 0$. Jadi terdapat fungsi-fungsi semikontinu bawah terbatas $u, v \geq 0$ pada $K$ sehingga $f=u-v$.

\section{PEMBAHASAN}

Pada bagian ini akan dibuktikan sifat aljabar Banach komutatif dengan elemen identitas pada kelas $D(K)$. Berdasarkan Definisi 1.1 di atas, beberapa langkah harus dibuktikan terlebih dahulu.

Berikut ini akan ditunjukkan bahwa $D(K)$ merupakan ruang linear.

Lemma 3.1 Diberikan ruang metrik separabel $K$, $D(K)$ merupakan ruang linear.

Bukti : Diambil sembarang $f, g \in D(K)$ dan skalar $\alpha$, maka terdapat fungsi-fungsi semikontinu bawah terbatas $u, v, s, t \geq 0$ pada $K$, dengan sifat $f=u-v$ dan $g=s-t$, sehingga diperoleh

1) $f+g=(u-v)+(s-t)=(u+s)-(v+t)$. Karena $u, s, t$ dan $v$ fungsi-fungsi semikontinu bawah, maka $u+s$ dan $v+t$ juga fungsi fungsi semikontinu bawah. Oleh karena itu, apabila $u^{\prime}=u+s$ dan $v^{\prime}=v+t$ maka diperoleh fungsi-fungsi semikontinu bawah terbatas $u^{\prime}, v^{\prime} \geq 0$ pada $K$, sehingga $f+g=$ $u^{\prime}-v^{\prime}$. Akibatnya $f+g \in D(K)$.

2) $\alpha f=\alpha(u-v)=\alpha u-\alpha v$. Apabila $\alpha \geq 0$, maka $\alpha u, \alpha v$ fungsi-fungsi semikontinu bawah. Oleh karena itu, apabila $u^{\prime}=\alpha u$ dan $v^{\prime}=$ $\alpha v$, maka diperoleh fungsi-fungsi semikontinu bawah terbatas $u^{\prime}, v^{\prime} \geq 0$ pada $K$, sehingga $\alpha f=u^{\prime}-v^{\prime}$. Dilain pihak, apabila $\alpha<0$, maka $-\alpha u$ dan $-\alpha v$ fungsi - fungsi semikontinu bawah. Karena itu, apabila $u^{\prime \prime}=-\alpha v$ dan $v^{\prime \prime}=$ $-\alpha u$, maka diperoleh fungsi - fungsi semikontinu bawah terbatas $u^{\prime \prime}, v^{\prime \prime} \geq 0$ pada $K$, sehingga $\alpha f=u^{\prime \prime}-v^{\prime \prime}$. Akibatnya, $\alpha f \in D(K)$.

Jadi, terbukti $D(K)$ ruang linear.?

Berikut diberikan definisi fungsi yang sangat berperan dalam pembahasan pada bagian ini.

Definisi 3.2 Diberikan ruang metrik separabel $K$, didefinisikan fungsi $\|.\|_{D}: D(K) \rightarrow \boldsymbol{R}$, dengan $\|f\|_{D}=\inf \left\{\|u+v\|_{\infty}: f=u-v\right.$, dengan $u, v$ $\geq 0$ fungsi-

fungsi semikontinu untuk setiap $f \in D(K)$.

$$
\text { bawah terbatas pada } K\} \text {, }
$$

Selanjutnya akan dibuktikan bahwa $D(K)$ merupakan ruang bernorma terhadap fungsi $\|.\|_{D}$. Terlebih dahulu dibuktikan beberapa lemma yang akan digunakan dalam pembuktian.

Lemma 3.3 Jika $f \in D(K)$ maka $\|f\|_{\infty} \leq\|f\|_{D}$.

Bukti : Diambil sembarang $f \in D(K)$ dan fungsifungsi semikontinu bawah terbatas $u, v \geq 0$ pada $K$, dengan sifat $f=u-v$. Menurut definisi norma supremum, diperoleh

$$
\begin{gathered}
\|f\|_{\infty}=\sup _{x \in K}|f(x)|=\sup _{x \in K}|u(x)-v(x)| \\
\leq \sup _{x \in K}|u(x)+v(x)|=\|u+v\|_{\infty} .
\end{gathered}
$$

Dengan kata lain, $\|f\|_{\infty}$ merupakan batas bawah dari himpunan

$\left\{\|u+v\|_{\infty}: f=u-v\right.$, dengan $u, v \geq 0$ fungsifungsi semikontinu bawah terbatas pada $K\}$

Oleh karena itu, diperoleh

$\|f\|_{\infty} \leq \inf \left\{\|u+v\|_{\infty}: f=u-v\right.$ dengan $u, v$

$$
\geq 0
$$

fungsi - fungsi semikontinu bawah terbataspada $K\}$.

Jadi, terbukti bahwa $\|f\|_{\infty} \leq\|f\|_{D}$.

Lemma 3.4 Jika $f \in D(K)$ dan $\alpha \in \boldsymbol{R}$ maka berlaku

$\left\{\|\alpha(u+v)\|_{\infty}: \alpha f=\alpha u-\alpha v\right.$, dengan $u, v \geq 0$ fungsi fungsi semikontinu bawah terbatas pada $K\}$ $=\left\{\|h+g\|_{\infty}: \alpha f=h-g\right.$, dengan $h, g \geq$ 0 fungsi - fungsi semikontinu bawah terbatas pada $K\}$.

Bukti : Diambil sembarang $f \in D(K)$ dan $\alpha \in \boldsymbol{R}$. Untuk kemudahan dalam pembuktian, namakan $A=\left\{\|\alpha(u+v)\|_{\infty}: \alpha f=\alpha u-\alpha v\right.$, dengan $u, v$ $\geq 0$

fungsi - fungsi semikontinu bawah terbatas pada $K\}$, dan

$B=\left\{\|h+g\|_{\infty}: \alpha f=h-g\right.$, dengan $h, g \geq 0$

fungsi - fungsi semikontinu bawah terbatas pada $K$ \}. 
Akan dibuktikan $A=B$. Diambil sembarang $a \in A$, maka terdapat fungsi-fungsi semikontinu bawah terbatas $u, v \geq 0$ pada $K$, dan $\alpha f=\alpha u-\alpha v$, sehingga diperoleh $a=\|\alpha(u+v)\|_{\infty}$. Dalam hal ini ada dua kemungkinan, yaitu $\alpha \geq 0$ atau $\alpha<0$.

Jika $\alpha \geq 0$ maka $\alpha u, \alpha v \geq 0$. Berarti terdapat fungsi - fungsi semikontinu bawah terbatas $h=\alpha u$ dan $g=\alpha v$ pada $K$, sehingga $\alpha f=h-g \quad$ dan diperoleh $\quad a=\|h+g\|_{\infty}$, dengan kata lain $a \in B$.

Jika $\alpha<0$ maka dapat dipilih fungsi-fungsi semikontinu bawah terbatas $h=-\alpha v$ dan $g=$ $-\alpha u$, sehingga $\alpha f=h-g$ dan diperoleh $a=$ $\|h+g\|_{\infty}$, dengan kata lain $a \in B$. Akibatnya, diperoleh $A \subseteq B$.

Sebaliknya, diambil sembarang $b \in B$, maka terdapat fungsi-fungsi semikontinu bawah terbatas $h, g \geq 0$ pada $K$ dengan $\alpha f=h-g$, sehingga diperoleh $b=\|h+g\|_{\infty}$. Apabila $\alpha=0$ maka jelas terbukti $B \subseteq A$. Selanjutnya, apabila $\alpha \neq 0$ maka dapat dipilih $u=\frac{h}{\alpha}$ dan $v=\frac{g}{\alpha}$. Dalam hal ini ada dua kemungkinan, yaitu $\alpha>0$ atau $\alpha<$ 0 .

Jika $\alpha>0$ maka diperoleh fungsi-fungsi semikontinu bawah terbatas $u, v \geq 0$ pada $K$ dan $\alpha f=\alpha u-\alpha v, \quad$ sehingga $\quad b=\|\alpha(u+v)\|_{\infty}$. Dengan kata lain, $b \in A$.

Jika $\alpha<0$ maka diperoleh

$$
\begin{aligned}
\alpha f & =h-g=\alpha u-\alpha v=(-\alpha v)-(-\alpha u) \\
& =\alpha(-v)-\alpha(-u) .
\end{aligned}
$$

Oleh karena itu, apabila $u^{\prime}=(-v)$ dan $v^{\prime}=(-u)$, maka diperoleh fungsi - fungsi semikontinu bawah terbatas $u^{\prime}, v^{\prime} \geq 0$ pada $K$ dan $\alpha f=\alpha u^{\prime}-$ $\alpha v^{\prime}$, sehingga $b=\left\|\alpha\left(u^{\prime}+v^{\prime}\right)\right\|_{\infty}$. Dengan kata lain, $b \in A$. Akibatnya diperoleh $B \subseteq A$. Jadi, terbukti $A=B$.

Seperti yang telah disebutkan sebelumnya, dengan menggunakan Lemma 3.3 dan Lemma 3.4, dapat dibuktikan bahwa fungsi $\|\cdot\|_{D}$ adalah norma pada $D(K)$.

Teorema 3.5 Fungsi $\|.\|_{D}$ adalah norma pada kelas $D(K)$.

\section{Bukti :}

(1). Akan dibuktikan bahwa $\|f\|_{D} \geq 0$, untuk setiap $f \in D(K)$, dan $\|f\|_{D}=0$ jika dan hanya jika $f=\mathbf{0}$.

Diambil sembarang $f \in D(K)$. Karena

$\|f\|_{D}=\inf \left\{\|u+v\|_{\infty}: f=u-v\right.$, dengan $u, v$ $\geq 0$

fungsi - fungsi semikontinu bawah terbatas pada $K$ \},

maka diperoleh $\|f\|_{D} \geq 0$. Selanjutnya, jika $\|f\|_{D}=0$ maka menurut Lemma 3.3 diperoleh $\|f\|_{\infty}=0$. Oleh karena itu, $f(x)=0$ untuk setiap $x \in K$, dengan kata lain $f=\mathbf{0}$. Sebaliknya, jika $f=\mathbf{0}$ maka terdapat fungsi-fungsi semikontinu bawah terbatas $u=\mathbf{0}$ dan $v=\mathbf{0}$, sehingga $f=$ $u-v=\mathbf{0}$, akibatnya diperoleh

$\|f\|_{D}=\inf \left\{\|u+v\|_{\infty}: f=u-v\right.$, dengan $u, v$ $\geq 0$

fungsi - fungsi semikontinu bawah terbatas pada $K\}=0$

(2). Akan dibuktikan $\|\alpha f\|_{D}=|\alpha|$. $\|f\|_{D}$, untuk setiap $f \in D(K)$ dan skalar $\alpha$.

Diambil sembarang $f \in D(K)$ dan $\quad \alpha \in \boldsymbol{R}$. Berdasarkan Lemma 3.4, diperoleh

$$
\begin{aligned}
& |\alpha| .\|f\|_{D}=|\alpha| \inf \left\{\|u+v\|_{\infty}: f=u-v,\right. \\
& \text { dengan } \\
& u, v \geq 0 \text { fungsi - fungsi semikontinu } \\
& \text { bawah terbatas pada } K\} \\
& =\inf \left\{|\alpha|\|u+v\|_{\infty}: f=u-v\right. \text {, dengan } \\
& u, v \geq 0 \text { fungsi - fungsi semikontinu } \\
& \text { bawah terbatas pada } K\} \\
& =\inf \left\{\|\alpha(u+v)\|_{\infty}: \alpha f=\alpha u-\alpha v\right. \text {, } \\
& \text { dengan } u, v \geq 0 \text { fungsi - fungsi } \\
& \text { semikontinu bawah terbatas } \\
& \text { pada } K\} \\
& =\inf \left\{\|h+g\|_{\infty}: \alpha f=h-g\right. \text { dengan } \\
& h, g \geq 0 \text { fungsi - fungsi semikontinu } \\
& \text { bawah terbatas pada } K\} \\
& =\|\alpha f\|_{D} \text {. }
\end{aligned}
$$

(3). Akan dibuktikan $\|f+g\|_{D} \leq\|f\|_{D}+\|g\|_{D}$, untuk setiap $f, g \in D(K)$.

Diambil $f, g \in D(K)$ dan $\varepsilon>0$ sembarang, maka terdapat fungsi - fungsi semikontinu bawah terbatas $u, v, s, t \geq 0$ dengan $f=u-v$ dan $g=$ $s-t$, sehingga berlaku

$\|u+v\|_{\infty}<\|f\|_{D}+\frac{\varepsilon}{2}$ dan $\|s+t\|_{\infty}<\|g\|_{D}+\frac{\varepsilon}{2}$.

Oleh karena itu, diperoleh

$$
\begin{aligned}
\|f\|_{D}+\|g\|_{D}+\varepsilon & >\|u+v\|_{\infty}+\|s+t\|_{\infty} \\
& \geq\|(u+v)+(s+t)\|_{\infty} \\
& =\|(u+s)+(v+t)\|_{\infty} \\
& \geq\|f+g\|_{D} .
\end{aligned}
$$

Karena berlaku untuk $\varepsilon>0$ sembarang, maka diperoleh

$$
\|f+g\|_{D} \leq\|f\|_{D}+\|g\|_{D} .
$$

Berdasarkan (1), (2), dan (3), maka terbukti bahwa fungsi $\|.\|_{D}$ adalah norma pada $D(K)$. [?

Pengertian norma pada $D(K)$ dapat juga disajikan lain, yang tertuang dalam teorema berikut ini.

Teorema 3.6 Fungsi $f \in D(K)$ jika dan hanya jika terdapat barisan $\left\{f_{n}\right\}$ di $C(K)$ dan $\sup _{x \in K} \sum_{n}\left|f_{n}(x)\right|<$ $\infty$ sehingga $\sum_{n} f_{n}=f$ titik demi titik. Lebih lanjut, $\|f\|_{D}=\inf \left\{\left\|\sum_{n=0}^{\infty}\left|f_{n}\right|\right\|_{\infty}:\left\{f_{n}\right\}_{n=0}^{\infty} \subset C(K)\right.$ dan 


$$
\begin{aligned}
& \sup _{x \in K} \sum_{n=0}^{\infty}\left|f_{n}(x)\right|<\infty \text { sehingga } \\
& \left.\sum_{n=0}^{\infty} f_{n}=f \text { titik demi titik }\right\} .
\end{aligned}
$$

Bukti : (Syarat perlu). Diketahui $f \in D(K)$, maka terdapat fungsi-fungsi semikontinu bawah terbatas $u, v \geq 0$ pada $K$, sehingga $f=u-v$. Karena $u$ fungsi semikontinu bawah terbatas, maka terdapat barisan $\left\{\varphi_{n}\right\} \subseteq C(K)$ sehingga $\varphi_{0} \leq \varphi_{1} \leq \varphi_{2} \leq \varphi_{3} \leq \cdots$ dengan $\varphi_{0}=\mathbf{0}$ dan $\left\{\varphi_{n}\right\}$ konvergen titik demi titik ke $u$. Oleh karena itu, diperoleh

$$
\begin{aligned}
& u(x)=\lim _{n \rightarrow \infty} \varphi_{n}(x) \\
& =\lim _{n \rightarrow \infty} \sum_{j=1}^{n}\left(\varphi_{j}-\varphi_{j-1}\right)(x)=\sum_{j=1}^{\infty}\left(\varphi_{j}-\right. \\
& \left.\varphi_{j-1}\right)(x),
\end{aligned}
$$

untuk setiap $x \in K$. Selanjutnya, karena $v$ juga fungsi semikontinu bawah terbatas, maka terdapat barisan $\left\{\psi_{n}\right\} \subseteq C(K)$ sehingga $\psi_{0} \leq$ $\psi_{1} \leq \psi_{2} \leq \cdots$ dengan $\psi_{0}=\mathbf{0}$ dan $\left\{\psi_{n}\right\}$ konvergen titik demi titik ke $v$. Oleh karena itu, diperoleh $v(x)=\lim _{n \rightarrow \infty} \psi_{n}(x)$

$=\lim _{n \rightarrow \infty} \sum_{j=1}^{n \rightarrow \infty}\left(\psi_{j}-\psi_{j-1}\right)(x)=\sum_{j=1}^{\infty}\left(\psi_{j}-\psi_{j-1}\right)(x)$, untuk setiap $x \in K$. Sehingga untuk sebarang $x \in$ $K$ diperoleh

$f(x)=u(x)-v(x)$

$=\sum_{j=1}^{\infty}\left(\varphi_{j}-\varphi_{j-1}\right)(x)-\sum_{j=1}^{\infty}\left(\psi_{j}-\psi_{j-1}\right)(x)$

$=\sum_{j=1}^{\infty}\left(\varphi_{j}-\varphi_{j-1}-\psi_{j}+\psi_{j-1}\right)(x)$.

Selanjutnya, namakan $f_{j}=\varphi_{j}-\varphi_{j-1}-\psi_{j}+\psi_{j-1}$, untuk setiap $j \in \boldsymbol{N}$ dengan $f_{0}=\mathbf{0}$, sehingga diperoleh barisan $\left\{f_{n}\right\} \subseteq \mathrm{C}(K)$. Oleh karena itu, $f(x)=\sum_{n=1}^{\infty} f_{n}(x)$, untuk setiap $x \in K$. Dilain pihak, karena $u$ dan $v$ terbatas, maka terdapat $M_{1}, M_{2}>0$ sehingga $|u(x)| \leq M_{1}$ dan $|v(x)| \leq M_{2}$, untuk setiap $x \in K$. Akibatnya, untuk sembarang $x \in K$ berlaku

$$
\begin{aligned}
\sum_{n=1}^{\infty}\left|f_{n}(x)\right| & =\sum_{n=1}^{\infty}\left|\left(\varphi_{n}-\varphi_{n-1}-\psi_{n}+\psi_{n-1}\right)(x)\right| \\
& \leq M_{1}+M_{2}
\end{aligned}
$$

Karena berlaku untuk sebarang $x \in K$, maka diperoleh $\sup \sum_{n=1}^{\infty}\left|f_{n}(x)\right|<\infty$. Dengan kata lain,

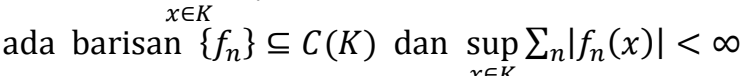
sehingga $\sum_{n} f_{n}=f$ titik demi titik. Oleh karena itu, diperoleh

$\|f\|_{D} \geq \inf \left\{\left\|\sum_{n=0}^{\infty}\left|f_{n}\right|\right\|_{\infty}:\left\{f_{n}\right\}_{n=0}^{\infty} \subset C(K)\right.$ dan $\sup \sum_{n=0}^{\infty}\left|f_{n}(x)\right|<\infty$$$
\text { sehingga } \sum_{n=0}^{\infty} f_{n}=f \text { titik demi titik\}. }
$$

(Syarat cukup). Diketahui barisan $\left\{f_{n}\right\} \subseteq C(K)$ dan $\sup \sum_{n=0}^{\infty}\left|f_{n}(x)\right|<\infty \quad$ sehingga $\quad \sum_{n=0}^{\infty} f_{n}=$ $x \in K$

$f$ titik demi titik.

Untuk sembarang $x \in K$, berlaku

$$
\begin{aligned}
& f(x)=\sum_{n=1}^{\infty} f_{n}(x)=\lim _{k \rightarrow \infty} \sum_{n=1}^{k} f_{n}(x) \\
& =\lim _{k \rightarrow \infty} \sum_{n=1}^{k}\left(f_{n}^{+}-f_{n}^{-}\right)(x) \\
& =\lim _{k \rightarrow \infty} \sum_{n=1}^{k}\left(f_{n}^{+}(x)-f_{n}^{-}(x)\right)
\end{aligned}
$$

$$
=\lim _{k \rightarrow \infty} \sum_{n=1}^{k}\left(f_{n}^{+}\right)(x)-\lim _{k \rightarrow \infty} \sum_{n=1}^{k}\left(f_{n}^{-}\right)(x)
$$$$
=\sum_{n=1}^{\infty}\left(f_{n}^{+}\right)(x)-\sum_{n=1}^{\infty}\left(f_{n}^{-}\right)(x) \text {. }
$$

Selanjutnya, namakan $u=\sum_{n=1}^{\infty}\left(f_{n}^{+}\right)$dan $v=$ $\sum_{n=1}^{\infty}\left(f_{n}{ }^{-}\right)$. Karena $f_{n}{ }^{+}, f_{n}{ }^{-} \geq 0$ maka diperoleh $u, v \geq 0$. Diperhatikan bahwa $\sum_{n=1}^{k}\left(f_{n}\right)^{+}(x) \leq$ $\sum_{n=1}^{k+1}\left(f_{n}\right)^{+}(x)$ untuk setiap $x \in K$, dan

$\lim _{k \rightarrow \infty} \sum_{n=1}^{k}\left(f_{n}\right)^{+}(x)=\sum_{n=1}^{\infty}\left(f_{n}\right)^{+}(x)$. Akibatnya, $u$ merupakan fungsi semikontinu bawah terbatas pada $K$. Dengan cara yang sama, diperoleh $v$ merupakan fungsi semikontinu bawah terbatas pada $K$. Oleh karena itu, terdapat fungsi-fungsi semikontinu bawah terbatas $u, v \geq 0$ pada $K$, sehingga $f=u-v$. Dengan kata lain, $f \in D(K)$. Akibatnya, diperoleh

$$
\begin{gathered}
\|f\|_{D} \leq \inf \left\{\left\|\sum_{n=0}^{\infty}\left|f_{n}\right|\right\|_{\infty}:\left\{f_{n}\right\}_{n=0}^{\infty} \subset C(K) \text { dan },\right. \\
\sup _{\mathrm{x} \in \mathrm{K}}^{\infty} \sum_{n=0}^{\infty}\left|f_{n}(x)\right|<\infty \text { sehingga } \\
\left.\sum_{n=0}^{\infty} f_{n}=f \text { titik demi titik }\right\} .
\end{gathered}
$$

Menggunakan Teorema 3.6, pengertian norma pada $D(K)$ dapat disajikan dalam bentuk lain, yang tertuang dalam teorema berikut.

Teorema 3.7 Fungsi $f \in D(K)$ jika dan hanya jika terdapat barisan $\left\{f_{n}\right\}$ di $C(K)$ dan $\mathrm{C}<\infty$, sehingga $\left\{f_{n}\right\}$ konvergen titik demi titik ke $f$ dengan $f_{0}=\mathbf{0}$ dan $\sum_{n=0}^{\infty}\left|f_{n+1}(x)-f_{n}(x)\right| \leq \mathrm{C}$ untuk setiap $x \in K$. Lebih lanjut,

$\|f\|_{D}=\inf \left\{\mathrm{C}:\left\{f_{n}\right\} \subseteq C(K), f_{0}=\mathbf{0}\right.$ dan

$\sum_{n=0}^{\infty}\left|f_{n+1}(x)-f_{n}(x)\right| \leq C, \forall x \in$

$K$, sehingga $\left\{f_{n}\right\}$

konvergen titik demi titik ke f\}.

Bukti : (Syarat perlu). Diketahui $f \in D(K)$ maka menurut Teorema 3.6, terdapat barisan $\left\{g_{n}\right\} \subseteq$ $C(K)$, sehingga $\sum_{n} g_{n}=f$ titik demi titik dan $\sup \sum_{n}\left|g_{n}(x)\right|<\infty$.

Namakan C $=\sup _{x \in K} \sum_{n}\left|g_{n}(x)\right|$, dan untuk setiap $n \in$ $\boldsymbol{N}$ dibentuk $f_{n}=\sum_{i=1}^{n} g_{i}$ dengan $f_{0}=\mathbf{0}$, maka diperoleh barisan $\left\{f_{n}\right\}$ di $C(K)$ dan $\left\{f_{n}\right\}$ konvergen titik demi titik ke $f$. Untuk sembarang $x \in K$ diperoleh

$\sum_{n=0}^{\infty}\left|f_{n+1}(x)-f_{n}(x)\right|$

$=\sum_{n=0}^{\infty}\left|\sum_{i=1}^{n+1} g_{i}(x)-\sum_{i=1}^{n} g_{i}(x)\right|$

$=\sum_{n=0}^{\infty}\left|g_{n+1}(x)\right| \leq \mathrm{C}$.

Dengan kata lain, terdapat barisan $\left\{f_{n}\right\} \subseteq C(K)$ dan $\mathrm{C}<\infty$, sehingga $\left\{f_{n}\right\}$ konvergen titik demi titik ke $f$ dengan $f_{0}=\mathbf{0}$ dan $\sum_{n=0}^{\infty} \mid f_{n+1}(x)-$ $f_{n}(x) \mid \leq \mathrm{C}$ untuk setiap $x \in K$. Oleh karena itu, diperoleh

$\|f\|_{D} \geq \inf \left\{C:\left\{f_{n}\right\} \subseteq C(K), f_{0}=\mathbf{0}\right.$ dan $\sum_{n=0}^{\infty}\left|f_{n+1}(x)-f_{n}(x)\right| \leq C, \forall x \in K$ sehingga $\left\{f_{n}\right\}$ konvergen titik demi titik ke $\left.f\right\}$.

(Syarat cukup). Untuk setiap $n \in \boldsymbol{N}$, dibentuk $g_{n}=f_{n+1}-f_{n}$ dengan $g_{0}=\mathbf{0}$. Akibatnya, 
diperoleh barisan $\left\{g_{n}\right\} \subseteq C(K)$, dan $\sum_{n=0}^{\infty} g_{n}=f$ titik demi titik. Selanjutnya, untuk sebarang $x \in$ $K$, diperoleh

$\sum_{n=0}^{\infty}\left|g_{n}(x)\right|=\sum_{n=0}^{\infty}\left|f_{n+1}(x)-f_{n}(x)\right| \leq \mathrm{C}<\infty$.

Karena berlaku untuk sembarang $x \in K$, maka diperoleh $\sup _{x \in K} \sum_{n}\left|g_{n}(x)\right|<\infty$. Dengan kata lain, terbukti $f \in D(K)$. Oleh karena itu, diperoleh $\|f\|_{D} \leq \inf \left\{\mathrm{C}:\left\{f_{n}\right\} \subseteq C(K), f_{0}=\mathbf{0}\right.$ dan $\sum_{n=0}^{\infty}\left|f_{n+1}(x)-f_{n}(x)\right| \leq C, \forall x \in K$ sehingga $\left\{f_{n}\right\}$ konvergen titik demi titik ke $\left.f\right\}$ Menggunakan Teorema 3.7, akan dibuktikan bahwa $D(K)$ merupakan ruang Banach.

Teorema 3.8 Diberikan ruang metrik separabel $K$, $D(K)$ merupakan ruang Banach.

Bukti : Berdasarkan Teorema 3.5, $\left(D(K),\|.\|_{D}\right)$ merupakan ruang bernorma, selanjutnya akan dibuktikan $D(K)$ lengkap. Diambil sebarang barisan Cauchy $\left\{f_{n}\right\} \subseteq D(K)$. Oleh karena itu, dapat diasumsikan $\left\|f_{n+1}-f_{n}\right\|_{D}<\frac{1}{2^{n}}$, untuk setiap $n \in \boldsymbol{N}$. Karena $f_{n+1}-f_{n} \in D(K)$, maka untuk setiap $n \in \boldsymbol{N}$ terdapat barisan $\left\{\varphi_{m}^{n}\right\}_{m=1}^{\infty}$ di $C(K)$, sehingga $\left\{\varphi_{m}^{n}\right\}_{m=1}^{\infty}$ konvergen titik demi titik ke $f_{n+1}-f_{n}$ dan memenuhi

$\sum_{m=0}^{\infty}\left|\varphi_{m+1}^{n}(x)-\varphi_{m}^{n}(x)\right| \leq \frac{1}{2^{n}}, \quad$ untuk setiap $x \in$ $K$.

Karena $\left\{f_{n}\right\}$ barisan Cauchy di $D(K)$, maka diperoleh $\left\|f_{m}-f_{n}\right\|_{\infty} \rightarrow 0$, untuk $n, m \rightarrow \infty$. Oleh karena itu, untuk setiap $x \in K$ diperoleh $\left\{f_{n}(x)\right\}$ barisan Cauchy di R. Karena $\mathbf{R}$ lengkap, maka untuk setiap $x \in K$, terdapat $f(x) \in \boldsymbol{R}$ sehingga $\left\{f_{n}(x)\right\}$ konvergen ke $f(x)$. Akibatnya diperoleh $\left\|f_{n}-f\right\|_{\infty} \rightarrow 0$.

Diambil sembarang $n_{0} \in \boldsymbol{N}$. Dibentuk $g_{n}=$ $f_{n+1}-f_{n}$, untuk setiap $n \in \boldsymbol{N}$ dan $\psi_{n}=\left(\varphi_{n}^{n_{0}}+\right.$ $\left.\cdots+\varphi_{n}^{l}\right)+\left(\varphi_{n+1}^{l+1}-\varphi_{n}^{l+1}\right)+\cdots+\left(\varphi_{n+1}^{n}-\varphi_{n}^{n}\right)$, untuk setiap $l, n \in \boldsymbol{N}$ dengan $n_{0} \leq l<n$. Oleh karena itu didapat barisan $\left\{\psi_{n}\right\} \subseteq C(K)$ dan berlaku

$$
\begin{aligned}
\sum_{n=n_{0}}^{\infty} g_{n} & =\lim _{k \rightarrow \infty} \sum_{n=n_{0}}^{k} g_{n} \\
& =\lim _{k \rightarrow \infty} \sum_{n=n_{0}}^{k}\left(f_{n+1}-f_{n}\right) \\
& =\lim _{k \rightarrow \infty}\left(f_{k+1}-f_{n_{0}}\right)=f-f_{n_{0}} .
\end{aligned}
$$

Selanjutnya, akan dibuktikan $f-f_{n_{0}} \in D(K)$. Untuk setiap $l, n \in \boldsymbol{N}$ dengan $n_{0} \leq l<n$, diperoleh

$$
\begin{aligned}
& \left\|\psi_{n}-\left(\varphi_{n}^{n_{0}}+\cdots+\varphi_{n}^{l}\right)\right\|_{\infty} \\
& =\left\|\left(\varphi_{n+1}^{l+1}-\varphi_{n}^{l+1}\right)+\cdots+\left(\varphi_{n+1}^{n}-\varphi_{n}^{n}\right)\right\|_{\infty} \\
& \leq \sum_{i=l+1}^{n} \frac{1}{2^{i}} \leq \frac{1}{2^{l}} .
\end{aligned}
$$

Oleh karena itu, apabila $n \rightarrow \infty$ maka untuk setiap $x \in K$ dan $l \geq n_{0}$, diperoleh

$$
\lim _{n \rightarrow \infty}\left|\psi_{n}(x)-\left(\varphi_{n}^{n_{0}}+\cdots+\varphi_{n}^{l}\right)(x)\right| \leq \frac{1}{2^{l}} .
$$

Akibatnya, diperoleh

$$
\begin{aligned}
g_{n_{0}}(x)+\cdots+g_{l}(x) & -\frac{1}{2^{l}} \leq \lim _{n \rightarrow \infty} \psi_{n}(x) \\
& \leq g_{n_{0}}(x)+\cdots+g_{l}(x)+\frac{1}{2^{l}} .
\end{aligned}
$$

Selanjutnya, apabila $l \rightarrow \infty$, maka diperoleh $\left\{\psi_{n}\right\}$ konvergen titik demi titik ke $f-f_{n_{0}}$. Disisi lain, diperoleh

$$
\begin{aligned}
& \sum_{n=0}^{\infty}\left|\psi_{n+1}(x)-\psi_{n}(x)\right| \leq \sum_{n=0}^{\infty} \mid \varphi_{n+1}^{n_{0}}(x)- \\
& \varphi_{n}^{n_{0}}(x) \mid+\cdots+ \\
& \sum_{n=0}^{\infty}\left|\varphi_{n+1}^{l}(x)-\varphi_{n}^{l}(x)\right|+\sum_{n=0}^{\infty} \mid \varphi_{n+1}^{l+1}(x)- \\
& \varphi_{n}^{l+1}(x) \mid+\cdots+ \\
& \sum_{n=0}^{\infty}\left|\varphi_{n+1}^{n}(x)-\varphi_{n}^{n}(x)\right|+\sum_{n=0}^{\infty} \mid \varphi_{n+2}^{l+1}(x)- \\
& \varphi_{n+1}^{l+1}(x) \mid \\
& +\cdots+\sum_{n=0}^{\infty}\left|\varphi_{n+2}^{n+1}(x)-\varphi_{n+1}^{n+1}(x)\right| \\
& \leq \sum_{i=n_{0}}^{n+1} \frac{1}{2^{i}} \leq \frac{1}{2},
\end{aligned}
$$

untuk setiap $x \in K$. Dengan demikian terdapat barisan $\left\{\psi_{n}\right\} \subseteq C(K)$ yang konvergen titik demi titik ke $f-f_{n^{\prime}}$, dan $\sum_{n=0}^{\infty}\left|\psi_{n+1}(x)-\psi_{n}(x)\right| \leq \frac{1}{2}$. Dengan kata lain benar bahwa $f-f_{n_{0}} \in D(K)$. Karena $D(K)$ ruang linear, maka diperoleh $f \in$ $D(K)$. Selanjutnya, berdasarkan asumsi diawal pembuktian, maka diperoleh

$$
\begin{aligned}
\left\|f-f_{n_{0}}\right\|_{D} & =\left\|\sum_{n=n_{0}}^{\infty} g_{n}\right\|_{D} \\
& =\left\|\sum_{n=n_{0}}^{\infty} f_{n+1}-f_{n}\right\|_{D} \\
& \leq \sum_{n=n_{0}}^{\infty}\left\|f_{n+1}-f_{n}\right\|_{D} \\
& \leq \sum_{n=n_{0}}^{\infty} \frac{1}{2^{n}} \leq \frac{1}{2^{n^{-1}}}, \text { untuk setiap } n_{0} \in \\
& \boldsymbol{N} .
\end{aligned}
$$

Karena berlaku untuk sembarang $n_{0} \in \boldsymbol{N}$, maka diperoleh barisan $\left\{f_{n}\right\}$ konvergen ke $f$. Jadi, terbukti $D(K)$ ruang Banach.

Berdasarkan Teorema 3.8, akan ditunjukkan bahwa $D(K)$ merupakan aljabar Banach komutatif dan mempunyai elemen identitas.

Teorema 3.9 Diberikan ruang metrik separabel $K$, $D(K)$ merupakan aljabar Banach komutatif dan mempunyai elemen identitas.

Bukti: Berdasarkan Teorema 3.8, $D(K)$ merupakan ruang Banach, selanjutnya akan dibuktikan $D(K)$ aljabar yang komutatif dan mempunyai elemen identitas.

1) Diambil sembarang $f, g, h \in D(K)$, maka terdapat fungsi - fungsi semikontinu bawah terbatas $u, v, w, x, y, z \geq 0$ pada $K$, sehingg $f=u-v, g=w-x$, dan $h=$ $y-z$. Oleh karena itu, diperoleh

$$
\begin{aligned}
f(g+h) & =(u-v)((w-x)+(y-z)) \\
& =(u-v)(w-x)+(u-v)(y-z) \\
& =f g+f h .
\end{aligned}
$$

Dengan kata lain, $f(g+h)=f g+f h$, untuk setiap $f, g, h \in D(K)$.

2) Diambil sembarang $f, g, h \in D(K)$, maka terdapat fungsi - fungsi semikontinu bawah 
terbatas $u, v, w, x, y, z \geq 0$ pada $K$, sehingga $f=u-v, g=w-x$, dan $h=$ $y-z$. Oleh karena itu, diperoleh

$$
\begin{aligned}
(g+h) f & =((w-x)+(y-z))(u-v) \\
= & (w-x)(u-v)+(y-z)(u-v) \\
= & g f+h f .
\end{aligned}
$$

Dengan kata lain, $(g+h) f=g f+h f$, untuk setiap $f, g, h \in D(K)$.

3) Diambil sembarang $f, g \in D(K)$ dan skalar $\alpha$, maka terdapat fungsi-fungsi semikontinu bawah terbatas $u, v, w, x \geq 0$ pada $K$, sehingga $f=u-v$, dan $g=w-x$. Oleh karena itu, diperoleh

$$
\begin{aligned}
& \alpha(f g)=\alpha((u-v)(w-x)) \\
& =(\alpha(u-v))(w-x)=(\alpha f) g .
\end{aligned}
$$

Dengan kata lain, $\alpha(f g)=(\alpha f) g$, untuk setiap $f, g \in D(K)$ dan skalar $\alpha$.

4) Diambil $f, g \in D(K)$ dan $\varepsilon>0$ sembarang, maka terdapat fungsi-fungsi semikontinu bawah terbatas $u, v, w, x \geq 0$ pada $K$, dengan $f=u-v$ dan $g=w-x$, sehingga berlaku

$\|u+v\|_{\infty}<\|f\|_{D}+\frac{\varepsilon}{\left(\|g\|_{D}+1\right)}$ dan

$\|w+x\|_{\infty}<\|g\|_{D}+\frac{\varepsilon}{\left(\|f\|_{D}+1\right)}$.

Oleh karena itu, diperoleh

$$
\begin{aligned}
\|f g\|_{D} & \leq\|(v x+u w)+(u x+v w)\|_{\infty} \\
& =\|(u+v)(w+x)\|_{\infty} \\
& \leq\|u+v\|_{\infty}\|w+x\|_{\infty} \\
& <\|f\|_{D}\|g\|_{D}+2 \varepsilon+\varepsilon^{2} .
\end{aligned}
$$

Karena berlaku untuk $\varepsilon>0$ sembarang maka diperoleh

$$
\|f g\|_{D} \leq\|f\|_{D}\|g\|_{D} .
$$

Dengan kata lain, $\|f g\|_{D} \leq\|f\|_{D}\|g\|_{D}$, untuk setiap $f, g \in D(K)$.

5) Diambil sembarang $f, g \in D(K)$, maka terdapat fungsi - fungsi semikontinu bawah terbatas $u, v, w, x \geq 0$ pada $K$, sehingga $f=u-v$ dan $g=w-x$. Oleh karena itu, diperoleh

$$
\begin{aligned}
f g & =(u-v)(w-x) \\
& =(w-x)(u-v)=g f .
\end{aligned}
$$

Dengan kata lain, $f g=g f$, untuk setiap $f, g \in D(K)$.

Dengan demikian, terbukti bahwa $D(K)$ merupakan aljabar Banach komutatif.

Selanjutnya akan dibuktikan $D(K)$ mempunyai elemen identitas.

Diambil sembarang $f \in D(K)$, maka terdapat fungsi-fungsi semikontinu bawah terbatas $u, v \geq 0$ pada $K$, sehingga $f=u-v$. Untuk sebarang $x \in K$ didefinisikan $e(x)=1$.
Akibatnya, diperoleh $e \in D(K)$. Oleh karena itu, diperoleh

$e f=e(u-v)=(u-v) e=u-v=f$.

Dengan kata lain, $e$ merupakan elemen identitas pada $D(K)$. Jadi, terbukti bahwa sifat aljabar Banach komutatif dan mempunyai elemen identitas berlaku pada kelas $D(K)$.

\section{PENUTUP}

Berdasarkan hasil pembahasan dapat disimpulkan bahwa kelas $D(K)$ mempunyai sifat aljabar Banach komutataif dan mempunyai elemen identitas.

Sifat aljabar Banach komutatif dapat pula diselidiki pada kelas bagian $B_{1}(K)$ lainnya, diantaranya kelas $B_{1 / 4}(K)$.

\section{DAFTAR PUSTAKA}

[1] Ash, R.B., 2007, Real Variables with Basic Metric Space Topology, Department of Mathematics University of Illionis at Urbana-Champaign.

[2] Dugundji, J., 1966, Topology, Allyn and Bacon, Inc., Boston.

[3] Farmaki, V., 1996, On Baire-1/4 Functions, Trans. Amer. Math. Soc, 348, 10.

[4] Gordon, R.A., 1994, The Integral of Lebesgue, Denjoy, Perron and Henstock, American Mathematical Society, USA.

[5] Haydon, R., Odell, E. dan Rosenthal, H.P., 1991, On Certain Classes of Baire-1 Functions with Applications to Banach Space Theory, Lecture Notes in Math., 1470, Springer, New York.

[6] Kreyszig, E., 1978, Introductory Functional Analysis with Applications, John Wiley and Sons, Inc., Canada.

[7] McShane, E.J., 1944, Integration, Princeton University Press, Princeton.

[8] Rosenthal, H.P., 1994, A Characterization of Banach Spaces Containing C0, J. Amer. Math. Soc, 7, 3, 707-748.

[9] Rosenthal, H.P., 1994, Differences of Bounded Semi-Continuous Functions I, http://www.arxiv.org/abs/math/9406217, 20 Juni 1994, diakses pada tanggal 27 Agustus 2009.

[10] Royden, H.L., 1989, Real Analysis, Macmillan Publishing Company, New York. 